\title{
Erratum to: "Glyceryl Tricaprate in Thylakoids of Stevia rebaudiana and Its Physiological Role" [Biology Bulletin 45, 31 (2018)]
}

\author{
N. I. Bondarev ${ }^{a, b}, *$, D. V. Kurilov ${ }^{c}$, T. A. Bondareva ${ }^{b}$, and A. M. Nosov ${ }^{a, d}$ \\ ${ }^{a}$ Timiryazev Institute of Plant Physiology, Russian Academy of Sciences, Moscow, 127276 Russia \\ ${ }^{b}$ Orel State University, Orel, 302026 Russia \\ ${ }^{c}$ Zelinskii Institute of Organic Chemistry, Russian Academy of Sciences, Moscow, 119991 Russia \\ ${ }^{d}$ Faculty of Biology, Moscow State University, Moscow, 119234 Russia \\ *e-mail: nikbond@inbox.ru \\ Submitted July 26, 2018; accepted for publication July 26, 2018
}

DOI: $10.1134 / \mathrm{S} 1062359019440018$

The affiliation under the symbol " $b$ " should read:

Orel State University, Orel, 302026 Russia

The original article can be found online at

10.1134/S1062359018010028 